\title{
MUSGOS DA GRUTA DE MIRASSOL, SÃO PAULO
}

Olga Yano ${ }^{1}$

Solange Xavier dos Santos ${ }^{2}$

Recebido em 16-09-91. Aceito em 10-09-93.

RESUMO - (Musgos da Gruta de Mirassol, São Paulo). Na Gruta de Mirassol foram encontradas 27 espécies de musgos pertencentes a 23 gêneros de 19 famílias. Racopilum tomentosum (Hedw.) Brid., Helicophyllum torquatum (Hook.) Brid. e Hyophila involuta (Hook.) Jaeg. \& Sauerb. são as espécies mais abundantes. Brachymenium acuminatum Harv., Cyclodictyon varians (Sull.) 0. Kuntze, Entodontopsis leucostega (Brid.) Buck \& Ireland, Fissidens mollis Mitt., F. weirii Mitt., Hyophila involuta (Hook.) Jaeg. \& Sauerb. e Trichosteleum fluviale (Mitt.) Jaeg. estão sendo referidas pela primeira vez para o estado de São Paulo.

Palavras-chave: musgos, Bryopsida, Gruta de Mirassol-SP, distribuição geográfica.

ABSTRACT - (Mosses from the Gruta de Mirassol, São Paulo State). Twenty-seven species of moss are described from the Gruta de Mirassol, State of São Paulo, Brazil; these are distributed among 23 genera and 19 families. Racopilum tomentosum (Hedw.) Brid., Helicophyllum torquatum (Hook.) Brid., and Hyophila involuta (Hook.) Jaeg. \& Sauerb. are the most common species. Brachymenium acuminatum Harv., Cyclodictyon varians (Sull.) O. Kuntze, Entodontopsis leucostega (Brid.) Buck \& Ireland, Fissidens mollis Mitt., F. weirii Mitt., and Hyophila involuta (Hook.) Jaeg. \& Sauerb. are cited for the firtst time from São Paulo State.

Key-words: mosses, Bryopsida, Gruta de Mirassol-SP, geographical distribution.

1 - Instituto de Botânica, Cx. P. 4005, 01061-970 São Paulo, SP, Brasil.

2 - Depto de Botânica, UNESP, Campus de São José do Rio Preto, 15055-000 São José do Rio Preto, SP, Brasil (Estagiária). 


\section{Introdução}

A Gruta de Mirassol localiza-se a noroeste da capital do estado de São Paulo (2049'02'S, 49³1'30'W), na cidade de Mirassol (573m de altitude), ocupando uma área de 173.109,63 m². Ela é uma depressão ou cratera cortada por um riacho perene de águas limpas e coberta por uma vegetação mesófila secundária. Ainda são encontradas árvores de grande porte fazendo parte da cobertura vegetal.

A gruta é uma Área de Proteção Ambiental Municipal (APA - Lei n 1394/86), de visitação pública, ficando ca. $500 \mathrm{~m}$ do centro da cidade de Mirassol, e ali transitam diariamente muitas pessoas, existindo inclusive uma área para pique-niques, o que torna a vegetação bastante alterada e conseqüentemente perturbada.

$\mathrm{O}$ objetivo do trabalho foi estudar as briófitas que ainda crescem nesta grota mesmo com a entrada constante do ser humano.

\section{Material e métodos} (1984a).

A metodologia de coleta e de preservação das amostras foi baseada em Yano

A coleta de material foi feita esporadicamente.

O material coletado está depositado uma parte no Herbário do Estado "Maria Eneyda P. Kauffmann Fidalgo" (SP) e com duplicatas no Herbário da UNESP Campus de São José do Rio Preto (SJRP).

As amostras foram identificadas com base nos trabalhos de Bartram (1949), Florschütz (1964), Griffin III (1979), Ochi (1980), Vital (1980), Crum \& Anderson (1981), Pursell (1984), Buck \& Ireland (1985) e comparadas com as já identificadas por especialistas.

O sistema de classificação foi baseado em Vitt (1984).

As espécies estão listadas em ordem alfabética dentro de cada gênero.

\section{Resultados e conclusões}

Estão sendo apresentadas 27 espécies de musgos encontradas na Gruta de Mirassol, sendo 7 (26\%) espécies de ocorrência nova para o estado de São Paulo: Brachymenium acuminatum Harv., Entodontopsis leucostega (Brid.) Buck \& Ireland, Cyclodictyon varians (Sull.) O. Kuntze, Fissidens mollis Mitt., F. weirii Mitt., Hyophila involuta (Hook.) Jaeg. \& Sauerb. e Trichosteleum fluviale (Mitt.) Jaeg.

Racopilum tomentosum (Hedw.) Brid., Helicophyllum torquatum (Hook.) Brid. e Hyophila involuta (Hook.) Jaeg. \& Sauerb. são as espécies mais abundantes.

Muitas das espécies encontradas são caracteristicas de locais mais abertos. 


\section{Erpodiaceae}

Erpodium beccarii C. Muell. ex Vent., Nuov. Giorn. Bot. Ital. 4: 18. 1872. Localidade-tipo: Etiópia Ilustração: Vital (1980)

Gametófitos verde-escuros, com leivas laxamente emaranhadas e delgadas. Filídios finamente adpressos ao caulídio quando secos, largamente agudos ou obtusos, com arista hialina terminal, 0,57-0,95 $\mathrm{mm}$ de comprimento sem arista. Células do filídio obscuras, pluripapilosas em ambas as faces, de paredes delgadas. Filídios periqueciais bem grandes e diferenciados, aristados, envolventes. Cápsula ereta, imersa. Caliptra campanuladamitrada, plicada. Opérculo reto. Ânulo persistente. Esporos esféricos, finamente papilosos, 24-26 $\mu \mathrm{m}$ de diâmetro.

Material examinado - São Paulo, Mirassol, sobre tronco vivo de Ligustrum sp., col. O. Yano \& T. Yano 4442, 17-VII-1982 (SP 172079).

Comentários - Erpodium beccarii cresce preferencialmente sobre troncos de árvores isoladas, formando leivas extensas e frouxamente entrelaçadas. É espécie que habita regiões geralmente urbanas.

O que caracteriza esta espécie são os seus filídios providos de aristas longas e hialinas que às vezes mascaram a cor da planta, dando às leivas uma cor cinza-azulada.

Erpodium coronatum (Hook. \& Wils) Mitt., J. Linn. Soc. Bot. 12: 403. 1869.

Basiônimo: Anictangium coronatum Hook. \& Wils, J. Bot. London 3: 150. 1844. Localidade-tipo: Equador

Ilustração: Vital (1980)

Gametófitos verde-claros a verde-escuros, leivas geralmente de forma circular, pouco densas. Filídios fortemente adpressos ao caulídio e imbricados quando secos, patentes quando úmidos, côncavos, com abrupto acúmem terminal, 0,8-1,3 x 0,5-0,8 mm. Células do filídio lisas, às vezes com algumas poucas papilas, as superiores irregulares e de paredes espessas, 16-32 $\mu \mathrm{m}$ de diâmetro, a maioria ovado-hexagonais, 17-34 x 20-37 $\mu \mathrm{m}$. Cápsula ereta, imersa, ovóide-cilíndrica, $1,25-1,70 \mathrm{~mm}$ de comprimento. Caliptra campanulada-mitrada, não papilosa. Opérculo ereto. Ânulo amplo com 3-4 fileiras de células grandes amarelo-pálidas, peristômio rudimentar. Esporos esféricos, quase lisos, $26-45 \mu \mathrm{m}$ de diâmetro.

Material examinado - São Paulo, Mirassol, sobre tronco vivo de Ligustrum sp., col. O. Yano \& T. Yano 4437, 17-VII-1982 (SP 172074); idem, Gruta de Mirassol, sobre tronco vivo, caído de Bombacaceae, col. O. Yano \& T. Yano 4444, 17-VII-1982 (SP 172081); idem, epixílico, sobre pau podre caído na beira da trilha, col. S.X. dos Santos 182, 18VII-1990 (SJRP 3291). 
Comentários - Erpodium coronatum cresce geralmente sobre casca dos troncos de árvores vivas, mais raramente sobre rochas e tronco podre.

A espécie é caracterizada pela leiva pouco extensa de forma circular. $\mathrm{O}$ gametófito é mais robusto que o de E. glazioui, quando fértil a cápsula ovóide-cilindrica imersa nos filídios periqueciais; caliptra campanulada-mitrada, plicada; ânulo amplo com 3-4 fileiras de células grandes.

Embora E. coronatum seja muito freqüente e abundante no N e NW de São Paulo, apenas 3 amostras férteis foram encontradas na região estudada.

Erpodium glazioui Hampe, Vidensk. Meddr dansk naturh. Foren. sér. 3, 4: 54. 1872. Localidade-tipo: Brasil

Ilustração: Vital (1980)

Gametófitos delicados, verdes a verde-amarelados; rizóides em pequenos feixes na parte ventral; leivas de forma irregular variando muito em extensão e sempre delgadas. Filídios frouxamente adpressos quando secos, patentes e laxamente complanados quando úmidos, oval-alongados a largamente ovais com ápice agudo ou obtuso, $0,5-0,9 \times 0,35$ $0,55 \mathrm{~mm}$. Células do filídio lisas, de paredes delgadas, com utrículos, as superiores e medianas rômbicas, $20-40 \times 13-23 \mu \mathrm{m}$, as basais centrais pouco maiores, alongadas verticalmente, retangulares, hexagonais a rômbicas, $35-50 \times 13-27 \mu \mathrm{m}$. Cápsula ereta, brilhante, com a parte superior emergente, castanha pálido-amarelada, oblongo-cilíndrica, $0,9-1,4 \times 0,4-0,7 \mathrm{~mm}$. Seta castanha, $0,4-0,7 \mathrm{~mm}$ de comprimento. Caliptra campanuladamitrada, não papilosa. Opérculo ereto e cônico. Ânulo e peristômio ausentes. Esporos esféricos, finamente papilosos, $18-35 \mu \mathrm{m}$ de diâmetro.

Material examinado - São Paulo, município de Mirassol, Gruta de Mirassol, epixílico, cobrindo toda a extensão de um tronco caído na saída da mata, aparentemente submetida à queimada, col. S.X. dos Santos 199, 1-V-1990 (SJRP 3302).

Comentários - Erpodium glazioui cresce sobre troncos de árvores e sobre os muros de pedras e tijolos de locais freqüentados por seres humanos como hortos, pomares, estradas, isto é, estão adaptadas às consequiências da presença humana.

Segundo Vital (1980) esta espécie ocorre associada a Frullania sp., Fabronia polycarpa Hook., e Dimerodontium mendozense Mitt.

A espécie é caracterizada pelos filídios adpressos, delicados, sempre delgados e, quando fértil, pela cápsula gimnóstoma no ápice dos gametófitos.

Helicophyllaceae

Helicophyllum torquatum (Hook.) Brid., Bryol. Univ. 2: 771. 1827. Basiônimo: Anictangium torquatum Hook., Musci Exot. 1: 41. 1818.

Localidade-tipo: América do Norte

Ilustração: Yano (1979) 
Gametófitos 30-40 mm de comprimento, prostrados, ramos unidirecionais, verdeamarelados à verde-escuros, brilhantes; arquegonióforos em forma de botões verde-amarelados envolvidos por tufos de filídios periqueciais terminais; face ventral dos ramos densamente tomentosa. Filídios dispostos quase em ângulo reto, em 2 séries laterais; filídios inferiores maiores, 1,4-1,6 $\times$ 0,4-0,5 mm, ligulados, obtusos, de base desigual, células quadrangulares, 20$30 \times 15-20 \mu \mathrm{m}$; filídios superiores menores, 0,4-0,6 $\times 0,2-0,3 \mathrm{~mm}$, costa robusta percurrente, com células quadráticas ou sub-quadráticas, $10-20 \times 8-20 \mu \mathrm{m}$, densamente clorofilladas e papilosas. Filídios pequenos entre os rizóides, na parte ventral do talo, esparsos, ovo-lanceolados $(0,7-)$ 4,5-1,0 x (0,2-)0,4-0,5 mm com células clorofiladas, 35-40 x 25-30 $\mu \mathrm{m}$. Cápsula gimnóstoma $1,5 \mathrm{~mm}$ de comprimento, ereta, cilíndrica, imersa nos filídios periqueciais; células da parede da cápsula retangulares, 30-40 × 25-30 um. Esporos castanho-esverdeados, 24-48 $\mu \mathrm{m}$ de diâmetro.

Material examinado - São Paulo, Mirassol, sobre tronco de Ligustrum sp., col. O. Yano \& T. Yano 4438, 4440, 17-VII-1982 (SP 170275; SP 172077); idem, Gruta de Mirassol, sobre tronco caído de Bombacaceae, col. O. Yano \& T. Yano 4443, 17-VII-1982 (SP 172080); idem, sobre tronco de árvore viva, col. O. Yano \& T. Yano 4447, 17-VII-1982 (SP 172083); idem, cobrindo a parede da grota principal, muito úmida, col. S.X. dos Santos 126, 1-V-1990 (SJRP 3252); idem, epífita, col. S.X. dos Santos 157, 1-V-1990 (SJRP 3275); idem, sobre tronco de árvore atacada por cupim, col. S.X. dos Santos 192, 18-VII-1990 (SJRP 3296); idem, epixílico, cobrindo toda a extensão de um tronco caído na saída de mata, aparentemente submetida à queimada, col. S.X. dos Santos 198, 1-V-1990 (SJRP 3301).

Comentários - Helicophyllum torquatum cresce principalmente em troncos de árvores com casca lisa, isoladas das grandes vegetações, ou em árvores bem esparsas que recebem bastante luz solar e possuem umidade razoável. Ocorre também sobre raizes tabulares, pedras, rochedos, paredões e outros substratos.

Quando seca, a espécie apresenta os filídios tipicamente enrolados a partir do ápice, como um báculo; tocando-se dos dois lados, quando umedecidos lentamente se expandem; os filídios periqueciais são sempre eretos.

Helicophyllum torquatum é exclusiva dos paises neotropicais e áreas de extensão neotropical, onde apresenta ampla distribuição.

Bryaceae

Brachymenium acuminatum Harv. in Hook., Icon. Pl. Rar. 1: 19. 1836.

Tipo: não definido

Ilustração: Ochi (1980); Gangulee (1974)

Gametófitos pequenos, terrestres, acima de $5 \mathrm{~mm}$ de altura, ramificados por inovações florais. Filídios patentes, imbricados, eretos com pontas patentes, ligeiramente contortos quando secos, ovados, oblongo-lanceolados, $1,1 \times 0,41 \mathrm{~mm}$, margem inteira. Costa forte, percurrente ou curto-excurrente em uma arista. células romboidais, paredes 
delgadas, $100 \times 10 \mu \mathrm{m}$ no ápice, geralmente sub-quadráticas a irregularmente arredondados, $19-95 \times 11-19 \mu \mathrm{m}$ na base.

Material examinado - São Paulo, município de Mirassol, Gruta de Mirassol, terrestre, solo arenoso, col. S.X. dos Santos 152, 1-V-1990 (SJRP 3270); idem, a margem da grota principal, muito úmida, col. S.X. dos Santos 195, 1-V-1990 (SJRP 3299).

Comentários - Brachymenium acuminatum cresce em solo ou sobre húmus cobrindo rochas ou paredes de rochas em lugares semi-abertos.

A espécie possui os filídios ovados com a costa percurrente ou curto-excurrente; ápice curto-acumunido; células da lâmina rombóide-hexagonais e sub-quadráticas na base.

Brachymenium acuminatum está sendo citada pela primeira vez para o estado de São Paulo.

\section{Bartramiaceae}

Philonotis glaucescens (Hornsch.) Broth., Bih. K. svensk. Vet. Akad. Handl. 21(3): 27. 1895.

Basiônimo: Bartramia glaucescens Hornsch., Fl. Bras. 1(2): 40. 1840.

Localidade-tipo: Brasil

Ilustração: Crum \& Anderson (1981)

Gametófitos verde-brilhantes ou amarelados, 5-10 mm de altura. Filídios geralmente eretos ou subsecundos quando secos, ereto-patentes quando úmidos, 0,4-0,7 mm de comprimento, lanceolados ou oblongos-lanceolados, ápice acuminado ou fracamente agudo; margem revoluta, serrulada; costa percurrente; células superiores lineares ou oblongolineares, papilosas na extremidade apical da célula.

Material examinado - São Paulo, município de Mirassol, Gruta de Mirassol, epífita sobre tronco vivo, col. S.X. dos Santos 186, 18-VII-1990 (SJRP 3294); idem, terrestre, solo argiloso e extremamente úmido, col. S.X. dos Santos 191, 18-VII-1990 (SJRP 3295); idem, sobre parede de cimento atrás da piscina, área úmida, col. S.X. dos Santos 204, 1V-1990 (SJRP 3307).

Comentários - Philonotis glaucescens cresce em solos ou rochas e barrancos úmidos.

A espécie é caracterizada pelos filídios lanceolados, ápice agudo a acuminado, costa percurrente, margens revolutas; células superiores do filídio lineares ou oblongo-lineares; gametófitos geralmente pequenos.

Racopilaceae

Racopilum tomentosum (Hedw.) Brid., Bryol. Univ. 2: 719. 1827.

Basiônimo: Hypnum tomentosum Hedw., Spec. Musc. 140. 1801. 
Localidade-tipo: Espanha (Hispania).

Ilustração: Yano (1984b)

Gametófitos verde-amarelados até verde-musgos, sem brilho; caulídio prostrado, tomentoso de rizóides. Filídios em 2 séries laterais e uma dorsal menor com espaçamento, retorcidos quando secos. Filídios laterais de base assimétrica, ovado-oblongos levemente apiculados, serreados, costa robusta excurrente, 1,7-2,0 x 1,0-1,2 mm; células arredondadohexagonais, 17-25 $\mu \mathrm{m}$. Filídios dorsais cordiforme-subulados, 1,3-0,5 $\mathrm{mm}$, arista quase com o mesmo comprimento do filídio; células arredondadas na base e rombo-hexagonais no ápice.

Material examinado - São Paulo, município de Mirassol, Gruta de Mirassol, no solo úmido e sombrio na base da árvore e barranco argiloso, col. O. Yano \& T. Yano 4458, 4461, 17-VII-1982 (SP 172091; SP 172093); idem, terrestre, solo arenoso, col. S.X. dos Santos 122, 123, 1-V-1990 (SJRP 3250; SJRP 3251); idem, solo argiloso-arenoso, col. S.X. dos Santos 151, 1-V-1990 (SJRP 3269); idem, epixílico umbrófilo, sobre pau podre caído no interior da mata, col. S.X. dos Santos 171, 14-VII-1990 (SJRP 3282); idem, terrestre, formando uma vasta cobertura de um barranco úmido, col. S.X. dos Santos 196, 1-V-1990 (SJRP 3300).

Comentários - Racopilum tomentosum cresce em locais bem úmidos, formando tapetes sobre solo humoso, pedras, rochas, madeiras ou troncos podres e troncos de árvores vivas nas matas sombrias.

A espécie é facilmente reconhecida pelo hábito dos filídios: os laterais com disposição dística e os dorsais cordiforme-subulados, menores e com a costa conspicuamente excurrente.

O tamanho é bastante variável a ponto de os extremos parecerem pertencer a espécies diferentes. A cor também varia, indo de verde-amarelado quando há maior luminosidade, a verde-musgo, quando cresce em locais sombrios e muito úmidos.

\section{Brachytheciaceae}

Rhynchostegium scariosum (Tayl.) Jaeg., Ber. S. Gall. Naturw. Ges. 1876-77: 374.1878.

Basiônimo: Hypnum scariosum Tayl., London J. Bot. 5: 65. 1846.

Localidade-tipo: Equador, Quito.

Ilustração: Bartram (1949).

Gametófitos verde-amarelados, livremente ramificados. Filídios espalhados, complanados, 1-2 mm de comprimento, ovalado-lanceolados, acuminados, serrulados; costa terminando $3 / 4$ abaixo do ápice. Células lineares, curtas e mais largas no ângulo basal e inserção com o caulídio.

Material examinado - São Paulo, município de Mirassol, Gruta de Mirassol, epífita sobre raiz de Palmeira, col. S.X. dos Santos 136, 1-V-1990 (SJRP 3259). 
Comentários - Rhynchostegium scariosum cresce sobre troncos de árvores, barrancos úmidos e pedras.

O tamanho é variável, geralmente delgado e os filídios pouco complanados, sempre menor que $2 \mathrm{~mm}$ de comprimento, ovalado-lanceolados.

Stereophyllaceae

Entodontopsis leucostega (Brid.) Buck \& Ireland, Nova Hedwigia 41: 103.1985.

Basiônimo: Leskea leucostega Brid., Bryol. Univ. 2: 333. 1827.

Localidade-tipo: Porto Rico

Ilustração: Buck \& Ireland (1985)

Gametófitos 10-30 mm de altura, em leivas verde-brilhantes ou amarelados. Filídios dos ramos e caulídios similares, ovado-lanceolados, ápice acuminado, os laterais simétricos, margem plana, 1,7-2,0 mm de comprimento; costa simples extendendo $1 / 2$ a $1 / 3$ do comprimento do filídio; células superiores longo-romboidais, 90-100 x 10-12 $\mu \mathrm{m}$; células alares fortemente diferenciadas, largas, quadráticas a retangulares, 30-32 x 20-22 $\mu \mathrm{m}$, geralmente distribuídas de forma desigual.

Material examinado - São Paulo, município de Mirassol, Gruta de Mirassol, epífita, sobre tronco vivo, col. S.X. dos Santos 185, 18-VII-1990 (SJRP 3293); idem, sobre raiz viva a beira da trilha, col. S.X. dos Santos 203, 1-V-1990 (SJRP 3306).

Comentários - Entodontopsis leucostega cresce geralmente sobre tronco podre, tronco vivo ou raízes vivas em locais bem iluminados de matas secundárias, úmidas.

Ela apresenta os filídios laterais simétricos; células alares diferenciadas em número mais ou menos igual sobre ambos os lados da costa; filídios geralmente acuminados; quando fértil possui a cápsula inclinada; gametófitos brilhantes.

Está sendo citada pela primeira vez para o estado de São Paulo.

Stereophyllum radiculosum (Hook.) Mitt., J. Linn. Soc. Bot. 12: 542. 1869.

Basiônimo: Hookeria radiculosa Hook., Musci Exot. 1: 51.1818.

Localidade-tipo: Crepidines juxta Caripe

Ilustração: Buck \& Ireland (1985)

Gametófitos 10-30 mm de comprimento, complanados a subjuláceos com pseudo parafilia filamentosa. Filídios oblongo-ovados, côncavos, 2,0-2,2 $\mathrm{mm}$ de comprimento, ápice abruptamente agudo a obtuso, algumas vezes apiculado, margens planas, inteiras ou serruladas no ápice; costa simples estendendo $2 / 3$ a $3 / 4$ do comprimento; células superiores romboidais $25-28 \times 12-15 \mu \mathrm{m}$, unipapilosas sobre o lúmem, algumas vezes lisas; células alares fortemente diferenciadas, quadráticas a retangulares ou transversalmente alongadas, $10-15 \times 8-10 \mu \mathrm{m}$, estendendo sobre a superfície adaxial da costa. 
Material examinado - São Paulo, município de Mirassol, Gruta de Mirassol, sobre tronco de árvore viva, col. O. Yano \& T. Yano 4448, 17-VII-1982 (SP 172084); idem, sobre tronco podre na mata, col. O. Yano \& T. Yano 4451, 17-VII-1982 (SP 172086); idem, na base do tronco de árvore viva, col. O. Yano \& T. Yano 4455, 17-VII-1982 (SP 172089); idem, epífita sobre raiz viva, col. S.X. dos Santos 155, 164, 1-V-1990 (SJRP 3273; SJRP 3280); idem, epixílico, semi-umbrófila sobre pau podre caído no interior da mata, col. S.X. dos Santos 176, 14-VII-1990 (SJRP 3287); idem, epífita, col. S.X. dos Santos 183, 18-VII-1990 (SJRP 3292): idem, epífita, na base de tronco vivo, col. S.X. dos Santos 200, 1-V-1990 (SJRP 3303).

Comentários - Stereophyllum radiculosum cresce em troncos caídos e rochas de matas úmidas.

A espécie é distinta pelas células romboidais curtas ou isodiamétricas, freqüentemente unipapilosas sobre o lúmem; costa até 2/3-3/4 do comprimento do filídio.

\section{Hypnaceae}

Chryso-hypnum diminutivum (Hampe) Buck, Brittonia 36: 182. 1984.

Basiônimo: Hypnum diminutivum Hampe, Linnaea 20: 86. 1847.

Localidade-tipo: Venezuela, Caracas

Ilustração: Crum \& Anderson (1981)

Gametófitos crispados, subpinados. Filídios eretos ou largo-patentes, 1,0-1,1 mm de comprimento, ovados, ápice acuminado, arredondado na base e algumas vezes decurrentes, margem mais ou menos sinuoso-serrulada, costa delgada. Células lineares ou oblongo-lineares, papilosas por causa da projeção na parte superior; células alares pequenas e subquadrátricas em poucas a várias fileiras.

Material examinado - São Paulo, município de Mirassol, Gruta de Mirassol, no barranco arenoso escorrendo água, col. O. Yano \& T. Yano 4465, 17-VII-1982 (SP 172095); idem, epixílico, semi-umbrófilo, sobre pau caído no interior de mata, col. S.X. dos Santos 175, 14-VII-1990 (SJRP 3286).

Comentários - Chryso-hypnum diminutivum cresce sobre troncos caídos, barrancos e troncos de árvores vivas.

A espécie pode ser facilmente reconhecida pela papila dorsal proeminente nas células do filídio.

Isopterygium tenerum (Sw.) Mitt., J. Linn. Soc. Bot. 12:499. 1869.

Basiônimo: Hypnum tenerum Sw., Fl. Ind. Occ. 3:1817. 1806.

Localidade-tipo: Jamaica

Ilustração: Crum \& Anderson (1981)

Gametófitos subpinados com pseudo parafilia filiforme, papilosa. Filídios geralmente patentes ou ereto-patentes e complanados, os laterais são simétricos, 0,7-1,0(1-7) $\mathrm{mm}$ de 
comprimento, oblongo-lanceolados, ápice acuminado inteiro a serrulado na extremidade; células pouco laxas no ângulo basal.

Material examinado - São Paulo, município de Mirassol, Gruta de Mirassol, cobrindo a parede da grota principal, muito úmida, col. S.X. dos Santos 127, 140, 1-V-1990 (SJRP 3253; SJRP 3263); idem, cobrindo parede argiloso-arenosa da grota principal, excessivamente úmido, semi-umbrófila, col. S.X. dos Santos 179, 14-VII-1990 (SJRP 3289).

Comentários - Isopterygium tenerum cresce sobre troncos caídos, na base dos troncos de árvores e sobre o solo (especialmente arenoso).

É extremamente variável e dificil de caracterizar, os filídios são ereto-patentes e distintamente complanados $\mathrm{e}$ as células alares são algumas vezes diferenciadas. Os gametófitos são de aparência muito delicada, mais delgados, as leivas mais laxas.

Vesicularia vesicularis (Schwaegr.) Broth., Naturl. Pflanzenfam. 1(3): 1094. 1908.

Basiônimo: Hypnum vesiculare Schwaegr., Spec. Musc. Suppl. 2(2): 167. 1827.

Localidade-tipo: Jamaica

Ilustração: Crum \& Anderson (1981).

Gametófitos verde-amarelados, ramos livres e freqüentemente pinados. Filídios complanado-patentes; os ventrais do ramo lanceolados, agudos ou acuminados, $0,8-1,0 \mathrm{~mm}$ de comprimento, margem plana subinteira; células laxamente oblongo-romboidais, 70-100 x 13 $\mu \mathrm{m}$; os laterais do ramo oblongo-ovados a ovado-lanceolados, ápice agudo a fortemente acuminado, 0,8-1,0 mm de comprimento, margem plana, serrulada em direção ao ápice; células superiores pelúcidas, laxamente oblongo-hexagonais, 33-35 x 13-17 $\mu \mathrm{m}$.

Material examinado - São Paulo, município de Mirassol, Gruta de Mirassol, cobrindo parede da grota principal, muito úmida, col. S.X. dos Santos 134, 1-V-1990 (SJRP 3258); idem, epífita, sobre tronco vivo, muito úmido à margem da grota, col. S.X. dos Santos 173, 14-VII1990 (SJRP 3284).

Comentários - Vesicularia vesicularis cresce geralmente no solo, húmus, tronco caído sobre solo humoso.

A espécie apresenta os filídios laterais mais largos que os ventrais, com células superiores oblongo-hexagonais, as junto da margem visivelmente estreitas.

Entodontaceae

Erythrodontium squarrosum (Hampe) Par., Ind. Bryol. ed. 2, 2: 159. 1904.

Basiônimo: Leptohymenium squarrosum Hampe, Flora 45: 456. 1862.

Localidade-tipo: Venezuela

Ilustração: Bartram (1949).

Gametófitos brilhantes, subpinados. Filídios densamente imbricados, firmemente adpressos, estrobiliformes quando secos, abaulado-ereto-patentes quando úmidos, um pouco 
encurvados, ovado-deltóides, ápice curto-acuminado, base larga, ovada, $1,1 \times 0,8 \mathrm{~mm}$, enerves. Células alares com pequenas, obscuras e transversalmente romboidais em $8-12$ fileiras na base do filídio.

Material examinado - São Paulo, município de Mirassol, Gruta de Mirassol, na base do tronco de árvore viva, col. O. Yano \& T. Yano 4450, 17-VII-1982 (SP 172085).

Comentários - Erythrodontium squarrosum cresce geralmente sobre o tronco ou raízes expostas, grandes árvores isoladas das vegetações.

Distingue-se pelos filídios firmente adpressos, curtos e largos, ápice apiculado ou curtoacuminado dando aos ramos o aspecto estrobiliforme característico. Quando fértil a seta é avermelhada.

Sematophyllaceae

Sematophyllum caespitossum (Hedw.) Mitt., J. Linn. Soc. Bot. 12:479. 1869.

Basiônimo: Leskea caespitosa Hedw., Spec. Musc. 233. 1801.

Localidade-tipo: Ilha Hispaniola

Ilustração: Crum \& Anderson (1981).

Gametófitos dourados, brilhantes, 20-25 mm de comprimento. Filídios densos, eretopatentes, de base larga e oblonga, ápice acuminado, $1,7 \times 0,7 \mathrm{~mm}$. Células alares diferenciadas, na série inferior oblongas estreitas, por cima mais ou menos retangulares, em 2 séries; na lâmina estreitas sub-paralelogrâmicas, agudas; no ápice um pouco menos agudas.

Material examinado - São Paulo, município de Mirassol, Gruta de Mirassol, sobre tronco de árvore viva na mata, col. O. Yano \& T. Yano 4459, 17-VII-1982 (SP 172092); idem, epífita, sobre raiz viva, col. S.X. dos Santos 154, 1-V-1990 (SJRP 3272).

Comentários - Sematophyllum caespitosum cresce sobre troncos caídos, no solo e pedras úmidas de matas.

A espécie é irregularmente ramificada, com ramos ascendentes; células do filídio ovadoromboidais.

Trichosteleum fluviale (Mitt.) Jaeg., Ber. S. Gall. Naturw. Ges. 1876-77: 419. 1878.

Basiônimo: Sematophyllum fluviale Mitt., J. Linn. Soc. Bot. 12: 493. 1869.

Localidade-tipo: Nova Granata

Ilustração: Griffin III (1979).

Gametófitos pequenos 3-5 mm de comprimento, verde-pálidos, irregularmente ramificados, complanados. Filídios oblongo-lanceolados, ápice curto-acuminado até mais ou menos obtuso, côncavo, $0,9 \mathrm{~mm}$ de comprimento. Células linear-romboidais, com uma grande papila no centro do lúmem. 
Material examinado - São Paulo, município de Mirassol, Gruta de Mirassol, epixílico, sobre tronco em decomposição, col. S.X. dos Santos 158, 159, 1-V-1990 (SJRP 3276; SJRP 3277); idem, umbrófilo, sobre pau podre caído no interior da mata, col. S.X. dos Santos 170, 14-VII-1990 (SJRP 3281).

Comentários - Trichosteleum fluviale cresce sobre troncos podres ou em decomposição na mata umbrófila.

Distingue-se pelo ápice curto-acuminado ou agudo e células linear-romboidais; células alares pouco diferenciadas.

Está sendo citada pela primeira vez para o estado de São Paulo.

Fabroniaceae

Fabronia ciliaris (Brid.) Brid. var. polycarpa (Hook.) Buck, Brittonia 35(3):251. 1983. Basiônimo: Fabronia polycarpa Hook., Musci Exot. 1: 3. 1818.

Localidade-tipo: Colômbia

Ilustração: Buck (1983)

Gametófitos densamente cespitosos, sub-eretos. Filídios eretos, adpressos, eretopatentes quando úmidos, ovados estreitamente acuminados, $0,65 \times 0,3 \mathrm{~mm}$. Costa até acima do meio da lâmina; células alares quadráticas, as demais sub-hexagonais a subelípticas, no ápice algumas estreitas e alongadas; margem inteira.

Material examinado - São Paulo, Mirassol, sobre tronco vivo de Ligustrum sp., col. O. Yano \& T. Yano 4439, 4441, 17-VII-1982 (SP 172076; SP 172078).

Comentários - Fabronia ciliaris var. polycarpa cresce geralmente sobre tronco de árvores geralmente isoladas das matas densas ou sobre árvores de parques e jardins.

A espécie possui os filídios mais ou menos ovados, de ápice acuminado e margem tipicamente inteira; células com paredes delgadas. Quando fértil os dentes do peristômio são mais curtos e obtusos.

Leucodontaceae

Pseudocryphaea flagellifera (Brid.) Britt. in Broth., Naturl.

Pflanzenfam. ed. 2. 11:98. 1925.

Basiônimo: Pilotrichum flagelliferum Brid., Bryol. Univ. 2: 259. 1827.

Localidade-tipo: São Domingos

Ilustração: Yano et al. (1987).

Gametófitos secundários dendróides, 50-60 mm de comprimento, ramos terciários alongados com ramos flagelíferos. Filídios imbricados quando secos, ovalados, breveacuminados; margem plana, serrilhada apicalmente, costa delgada terminando perto do 
ápice (percurrente); dorso superior com células linear-romboidais, fracamente papilosas; ângulo basal com células arredondadas, sinuosas e incrassadas em 10-12 fileiras.

Material examinado - São Paulo, município de Mirassol, Gruta de Mirassol, em tronco podre formando pequenos tufos, col. O. Yano \& T. Yano 4454, 17-VII-1982 (SP 172088); idem, epífita, col. S.X. dos Santos 160, 1-V-1990 (SJRP 3278).

Comentários - Pseudocryphaea flagellifera cresce geralmente sobre troncos de grandes árvores vivas de florestas mais abertas.

A espécie apresenta 0 gametófito secundário dendróide, com presença de ramos flageliformes no ápice. A base do filídio apresenta 10-12 fileiras de células diferenciadas formando os ângulos basais.

\section{Meteoriaceae}

Papillaria nigrescens (Hedw.) Jaeg., Ber. S. Gall. Naturw. Ges. 1875-76: 265. 1877.

Basiônimo: Hypnum nigrescens Hedw., Spec. Musc. 250. 1801.

Localidade-tipo: Jamaica

Ilustração: Crum \& Anderson (1981)

Gametófitos emaranhados, verde-claros depois nigrescentes. Filídios adpressos, cordiformes, ondulados, ápice estreito-longo-acuminado. Costa até a metade da lâmina. Células alares retangulares e quadráticas, as da lâmina oblongo-hexagonais, as do ápice estreitas e longas.

Material examinado - São Paulo, município de Mirassol, Gruta de Mirassol, em tronco de árvore viva na mata, col. O. Yano \& T. Yano 4452, 17-VII-1982 (SP 172087); idem, sobre casca de árvore morta na mata, col. O. Yano \& T. Yano 4457, 17-VII-1982 (SP 172090).

Comentários - Papillaria nigrescens cresce pendente sobre árvores; é distinta pelos filídios adpressos densamente dispostos e estreitamente acuminados. Algumas vezes parte dos ramos são pretos, daí o nome da espécie.

\section{Neckeraceae}

Neckeropsis undulata (Hedw.) Reichdt., Reise Oesterr. Freg. Novara Bot. 1: 181. 1870. Basiônimo: Neckera undulata Hedw., Spec. Musc. 201. 1801.

Localidade-tipo: Jamaica

Ilustração: Florschütz-de Waard (1986)

Gametófitos verde-amarelados, complanados. Filídios disticamente dispostos, oblongos, assimétricos, ápice truncado, inteiro, fortemente ondulados transversalmente. Costa simples 
até acima do meio. Células basais paralelogrâmicas estreito-alongadas, as superiores parenquimáticas e angulosas.

Material examinado - São Paulo, município de Mirassol, Gruta de Mirassol, epífita, col. S.X. dos Santos 161, 1-V-1990 (SJRP 3279).

Comentários - Neckeropsis undulata cresce em troncos de árvores vivas ou em pedras no interior de florestas úmidas.

A espécie é facilmente reconhecida pelo ápice truncado, pelas fortes ondulações transversais do filídio e quando fértil pelos filídios periqueciais interiores lineares e longos.

Hookeriaceae

Cyclodictyon varians (Sull.) O. Kuntze, Rev. Gen. Pl. 2: 835. 1891.

Basiônimo: Hookeria varians Sull., Proc. Am. Sc. Arts Sc. 5: 285. 1861.

Localidade-tipo: Cuba

Ilustração: Crum \& Anderson (1981)

Gametófitos pequenos, brilhantes, amarelados ou verde-claros. Filídios oblongo-ovados ou oblongo-lanceolados, ápice agudo ou acuminado, inteiro ou às vezes serrulado. Costa delgada, dupla, terminando ca. 2/3-3/4 do filídio, lisa ou às vezes mais ou menos serrulada acima; células superiores oblongo-hexagonais, $29-40 \mu \mathrm{m}$ de largura; uma fileira de células marginais estreitas, simples, formando a borda do filídio.

Material examinado - São Paulo, município de Mirassol, Gruta de Mirassol, cobrindo parede da grota principal, muito úmida, col. S.X. dos Santos 138, 1-V-1990 (SJRP 3261); idem, terrestre, solo argiloso à margem da grota principal, col. S.X. dos Santos 142, 1-V-1990 (SJRP 3264); idem, epífita, umbrófita, sobre raiz úmida à margem da grota principal, col. S.X. dos Santos 143, 1-V-1990 (SJRP 3265); epixílico, sobre pau podre caído no interior da mata, col. S.X. dos Santos 172, 14-VII-1990 (SJRP 3283); idem, cobrindo parede argilo-arenosa da grota principal, muito úmido, semi-umbrófila, col. S.X. dos Santos 180, 14-VII-1990 (SJRP 3290).

Comentários - Cyclodictyon varians cresce sobre solo úmido, rochas, paredes de pedras, paus podres, provavelmente calcífila.

A espécie apresenta os filídios oblongo-ovados ou oblongo-lanceolados de ápice agudo ou acuminado; células lisas laxas. Costa dupla e longa, margem bordeada por uma fileira de células lineares.

Está sendo citada pela primeira vez para o estado de São Paulo.

\section{Pottiaceae}

Hyophila involuta (Hook.) Jaeg. \& Sauerb., Ber. St. Gall. Naturw. Ges. 1871-72: 354. 1873. Basiônimo: Gymnostomum involutum Hook., Musci Exot. 2: 154. 1819. 
Localidade-tipo: Nepal

Ilustração: Crum \& Anderson (1981)

Gametófitos 5-10(-20) $\mathrm{mm}$ de altura, verde-escuros a marrom-avermelhados ou quase pretos, de forma mais ou menos rosulada. Filídios subtubulosos e patentes com ápice irregularmente incurvado quando seco, côncavos, 1,5-3,0 mm de comprimento. Costa simples, castanha; células superiores verde-escuras, pequenas, sub-quadráticas e hexagonal-arredondadas, 7-9 $\mu \mathrm{m}$; células da base curto-retangulares, paredes firmes, pálidas ou hialinas.

Material examinado - São Paulo, município de Mirassol, Gruta de Mirassol, terrestre, solo arenoso e muito úmido, col. S.X. dos Santos 129, 130, 1-V-1990 (SJRP 3255; SJRP 3256); idem, sobre escada de pedra, área pouco úmida, col. S.X. dos Santos 148, 1-V1990 (SJRP 3266); idem, sobre muro de cimento, col. S.X. dos Santos 153, 1-V-1990 (SJRP 3271); idem, solo argiloso, col. S.X. dos Santos 156, l-V-1990 (SJRP 3274); idem, terrestre, sobre fina camada de areia, col. S.X. dos Santos 194, 1-V-1990 (SJRP 3298); idem, sobre parede de cimento atrás da piscina, úmida, col. S.X. dos Santos 205, 1-V-1990 (SJRP 3308).

Comentários - Hyophila involuta cresce geralmente sobre rochas calcáreas e solo sobre rochas, freqüentemente sobre as margens dos rios, ou sobre pontes de concreto.

A espécie pode ser reconhecida facilmente pela maneira rosulada de crescimento; filídios obovados, escuros e enrolados nas margens quando secos. Em corte transversal do filídio a costa apresenta 2 bandas de estereídios que a distingue do gênero Neohyophila.

Está sendo citada pela primeira vez para o estado de São Paulo.

\section{Dicranaceae}

Dicranella cf. hilariana (Mont.) Mitt., J. Linn. Soc. Bot. 12:31. 1869.

Basiônimo: Dicranum hilarianum Mont., Ann. Sc. Nat. Bot. ser. 2, 12:52. 1839.

Localidade-tipo: Brasil

Ilustração: Crum \& Anderson (1981)

Gametófitos 3-8 mm de altura, castanho-amarelados a verde-escuros. Filídios eretoflexuosos a subsecundos, estreitamente lanceolados, ápice serrulado, margens mais ou menos recurvadas, costa forte subpercurrente; células variáveis, quadráticas a curtoretangulares, parede delgada, 5-7 x 11-55 um.

Material examinado - São Paulo, município de Mirassol, Gruta de Mirassol, terrestre, solo argilo-arenoso, col. S.X. dos Santos 150, 1-V-1990 (SJRP 3268).

Comentários - Dicranella cf. hilariana cresce no solo úmido exposto ao sol.

A espécie possui os filídios quase verticilados, costa terminando abaixo do ápice irregularmente denteado. 
Leucobryaceae

Octoblepharum albidum Hedw., Spec. Musc. 50. 1801.

Localidade-tipo: Jamaica

Ilustração: Yano (1975)

Gametófitos 5-15 (-20) mm de altura, verdes, verde-pálidos a esbranquiçados quando secos. Filídios patentes pouco recurvados, algumas vezes purpúreos na base, $5-8(-10) \mathrm{mm}$ de comprimento, ápice acuminado pouco denteado. Vista superficial do filídio: células do ápice retangulares, $40-45 \times 25-30 \mu \mathrm{m}$, da região mediana retangulares, $50-55 \times 27-30 \mu \mathrm{m}$, da base retangulares, $60-65 \times 30-35 \mu \mathrm{m}$. Corte transversal da costa: ápice 4 ( 2 e 2), região mediana 68 (3-4 e 3-4), base 7 (2 e 3-5) camadas de leucocistos, respectivamente acima e abaixo da camada clorocística.

Material examinado - São Paulo, município de Mirassol, Gruta de Mirassol, epífita, cobrindo toda a extensão de tronco vivo, col. S.X. dos Santos 201, 1-V-1990 (SJRP 3304).

Comentários - Octoblepharum albidum cresce em troncos de árvores vivas ou em decomposição, sobre pedras, solo arenoso, sobre rochas graníticas em lugares secos ou úmidos.

Pode ser facilmente reconhecida quando estéril pelo ápice do filídio denticulado e quando fértil pela cápsula ovóide com 8 dentes triangulares e seta de $10 \mathrm{~mm}$ de comprimento.

Fissidentaceae

Fissidens gardneri Mitt., J. Linn. Soc. Bot. 12: 593. 1869.

Localidade-tipo: Brasil

Ilustração: Pursell (1984)

Gametófitos pequenos ca. 3-5 mm de altura. Filídios geralmente encaracolados em direção ao ápice, oblongos ca. 0,35-1,2 mm de comprimento, ápice arredondado; margem crenulada; costa geralmente esporada acima, terminando bem abaixo do ápice, estendendo somente $0,4-0,7$ da distância entre a lâmina vaginante e 0 ápice do filídio; células da lâmina arredondado-hexagonais, 6,0-7,5 $\mu \mathrm{m}$ de comprimento.

Material examinado - São Paulo, município de Mirassol, Gruta de Mirassol, sobre tronco grande vivo de Ficus sp., col. O. Yano \& T. Yano 4446, 17-VII-1982 (SP 172082); idem, terrestre, à margem da grota principal, muito úmido, col. S.X. dos Santos 137, 1-V-1990 (SJRP 3260); idem, solo argiloso, escassamente úmido, col. S.X. dos Santos 149, 1-V-1990 (SJRP 3267).

Comentários - Fissidens gardneri cresce sobre troncos de árvores ou no solo úmido de matas secundárias.

Distingue-se pelo tamanho pequeno e os filídios com o ápice arredondado e margem crenulada. 
No estado de São Paulo só é conhecida da Gruta de Mirassol (Pursell \& Vital 1986).

Fissidens mollis Mitt., J. Linn. Soc. Bot. 12: 600. 1869.

Localidade-tipo: Jamaica

Ilustração: Florschütz (1964)

Gametófitos freqüentemente ramificados, $10-15 \mathrm{~mm}$ de altura. Filídios fortemente contortos quando secos, flácidos e laxamente patentes quando úmidos, até $4 \mathrm{~mm}$ de comprimento, linear-lanceolados, ápice curto-acuminado, fortemente bordeada em toda margem, a borda confluente até o ápice. Costa terminando abaixo do ápice; células laxas, hexagonais, paredes delgadas, ca. $40 \mu \mathrm{m}$ de comprimento.

Material examinado - São Paulo, município de Mirassol, Gruta de Mirassol, no barranco arenoso, escorrendo água (parte da bica), col. O. Yano \& T. Yano 4463, 17-VII-1982, det. R. Pursell (SP 172094); idem, sobre escada de pedra próximo à grota principal, col. S.X. dos Santos 121, 1-V-1990, det. O. Yano (SJRP 3249); idem, cobrindo parede argilo-arenosa da grota principal, excessivamente úmida, semi-umbrófila, col. S.X. dos Santos 178, 14-VII-1990, det. O. Yano (SJRP 3288).

Comentários - Fissidens mollis cresce geralmente no solo arenoso e úmido ou sobre rochas de florestas de altitude moderada.

A espécie é caracterizada pela borda continua até o ápice do filídio; filídios flácidos; células largas e laxas.

Está sendo citada pela primeira vez para o estado de São Paulo.

Fissidens weirii Mitt., J. Linn. Soc. Bot. 12: 602. 1869.

Localidade-tipo: Brasil, Paraná

Ilustração: Florschütz (1964)

Gametófitos 4-5(-10) $\mathrm{mm}$ de altura com 6-9(-12) pares de filídios, verde-amarelados. Filídios ereto-patentes, ca. $2 \mathrm{~mm}$ de comprimento, oblongo-lanceolados, ápice agudo ou apiculado, borda espessa geralmente levemente denteada pela projeção das papilas, algumas vezes lisas, a borda com bifurcações no lado interno superior da lâmina dorsal; costa pelúcida terminando logo abaixo do ápice; margem da lâmina apical minutamente crenulada quando não bordeada; células diminutas, 3-6 $\mu \mathrm{m}$, muito escuras, densas e minutamente papilosas.

Material examinado - São Paulo, município de Mirassol, Gruta de Mirassol, cobrindo parede da grota principal, área muito úmida col. S.X. dos Santos 128, 193, l-V-1990 (SJRP 3254; SJRP 3297); idem, col. S.X. dos Santos 139, 174, 14-VII-1990 (SJRP 3262; SJRP 3285); idem, cobrindo porção argilosa da parede da grota principal, col. S.X. dos Santos 133, l-V-1990 (SJRP 3257); idem, sobre parede de pedra, muito úmida, col. S.X. dos Santos 202, 206, 1-V-1990 (SJRP 3305; SJRP 3309). 
Comentários - Fissidens weirii cresce no solo ou pedras úmidas.

A espécie é reconhecida pelas células muito escuras pequenas e papilosas; a borda com bifurcações no lado interno superior principalmente na lâmina dorsal.

Está sendo citada pela primeira vez para o estado de São Paulo.

\section{Referências Bibliográficas}

Bartram, E.B. 1949. Mosses of Guatemala. Fieldiana Bot. 25:1-442.

Buck, W.R. 1983. A synopsis of the South American taxa of Fabronia (Fabroniaceae). Brittonia 35(3): 248-254.

Buck, W.R. \& Ireland, R.R. 1985. A reclassification of the Plagiotheciaceae. Nova Hedwigia 41:89-125.

Crum, H.A. \& Anderson, L.E. 1981. Mosses of eastern North America. New York: Columbia Univ. Press. Vol. 1-2: p.1-1328.

Florschütz, P.A. 1964. The mosses of Suriname part I. Leiden: E.J. Brill.

Florschütz-De Waard, J. 1986. Musci (part II). In Flora of Suriname. Leiden: E.J. Brill. p.273361.

Gangulee, H.C. 1974. A monograph: mosses of eastern India and adjacent regions. Índia: B.N. Das \& Books \& Allied. Vol. 4: xx-xxvi + 831-1134 p.

Griffin III, D. 1979. Guia preliminar para as briófitas freqüentes em Manaus e adjacências. Acta Amazonica 9 (supl. 3): 1-67.

Ochi, H. 1980. A revision of the Neotropical Bryoideae, Musci (First Part). J. Fac. Educ. Tottori Univ. 29(2): 49-154.

Pursell, R.A. 1984. A preliminary study of the Fissidens elegans complex in the Neotropics. J. Hattori Bot. Lab. 55:235-252.

Pursell, R.A. \& VITAL, D.M. 1986. Distributional adumbrations of Fissidens in the Neotropics. Bryologist 89(4):300-301.

Vital, D.M. 1980. Erpodiaceae (Musci) do Brasil. Univ. Estadual de Campinas. Dissertação de Mestrado.

Vitt, D.H. 1984. Classification of the Bryopsida. In Schuster, R.M. (ed.). New Manual of Bryology. Japão: Hattori Bot. Lab. p.696-759.

Yano, O. 1975. Leucobryaceae (Musci) do estado de São Paulo. Escola Paulista de Medicina. Dissertação de Mestrado.

Yano, O. 1979. Contribuição ao inventário dos Musci brasileiros: Helicophyllaceae. Rickia 8:7-16.

Yano, O. 1984a. Briófitas. In Fidalgo, O. \& Bononi, V.L.R. (coods). Técnicas de coleta, preservação e herborização de material botânico. São Paulo: Instituto de Botânica (Manual $\left.n^{\circ} 4\right)$. p. 27-30.

Yano, O. 1984b. Contribuição ao inventário dos Musci brasileiros: 3. Racopilaceae (Bryopsida, Isobryales). Revta brasil. Bot. 7(1):57-63.

Yano, O., Marinho, M.G.V., Mariz, G. 1987. Novas ocorrências de briófitas no nordeste brasileiro. Rickia 14:73-87. 